\title{
Learning to Read and Write: A Longitudinal Study of 54 Children From First Through Fourth Grades
}

\author{
Connie Juel \\ Department of Curriculum and Instruction \\ University of Texas at Austin
}

\begin{abstract}
My research focused on literacy development in children through fourth grade and followed an earlier study (Juel, Griffith, \& Gough, 1986). The Simple View of reading and writing received support in this earlier study and was examined in my current research. Of particular concern were these questions: Do the same children remain poor readers year after year? Do the same children remain poor writers year after year? What skills do the poor readers lack? What skills do the poor writers lack? What factors seem to keep poor readers from improving? What factors seem to keep poor writers from improving? The probability that a child would remain a poor reader at the end of fourth grade if the child was a poor reader at the end of first grade was .88. Early writing skill did not predict later writing skill as well as early reading ability predicted later reading ability. Children who became poor readers entered first grade with little phonemic awareness. By the end of fourth grade, the poor readers had still not achieved the level of decoding skill that the good readers had achieved at the beginning of second grade. Good readers read considerably more than the poor readers both in and out of school, which appeared to contribute to the good readers' growth in some reading and writing skills (e.g., in ideas for stories). Poor readers tended to become poor writers. The Simple View received support in accounting for reading and writing development through fourth grade.
\end{abstract}

This study examined the development of literacy in one elementary school with a large minority, low socioeconomic status population. The reading and writing development of 54 children was followed as they progressed from first through fourth grade. This in-depth examination of literacy acquisition in a microcosm of at-risk children attempted to answer the following questions: Do the same children remain poor readers year after year? Do the same children remain poor writers year after year? What skills do the poor readers lack? What skills do the poor writers lack? What factors seem to keep poor readers from improving? What factors seem to keep poor writers from improving?

I began my study by conceptualizing reading and writing from the Simple View (Gough \& Tunmer, 1986; Juel, Griffith, \& Gough, 1986). The development of those cognitive factors that are thought most responsible for literacy development within this view were closely followed in children who came to school with few reading and writing skills.

In the Simple View, reading ability is composed of two factors, decoding and comprehension. Decoding is the process

I thank Philip B. Gough for his insights on the Simple View of reading. I also want to acknowledge the effort of those who have worked on various aspects of this research: Cindy Farest, Priscilla Griffith, Ann Hall, Judy Leavell, Diane Roper/Schneider, and Gerry Shiel. I also want to thank the principal, teachers, and students of Houston Elementary School for 4 years of generosity in letting us into their classrooms.

A version of this article was presented at the annual meeting of the American Educational Research Association, New Orleans, April 1988.

Correspondence concerning this article should be addressed to Connie Juel, University of Texas at Austin, Department of Curriculum and Instruction, EDB 406, Austin, Texas 78712. that leads to word recognition. Learning to break the code of written text is partly dependent on being aware that words are composed of sequences of meaningless and somewhat distinct sounds (i.e., phonemes). This is often referred to as phonemic awareness. This realization is not necessary for understanding or producing speech. In speech production there is no clear distinction between phonemes, because one phoneme overlaps another. But phonemic awareness is necessary in learning to decode an alphabetic language, as print decoding depends on mapping phonemes to graphemes (i.e., letters in English). In school, phonics instruction attempts to make these correspondences explicit. Juel et al. (1986) found that phonics instruction is not effective unless children have (or quickly develop) some phonemic awareness at the beginning of first grade.

Phonemic awareness is not a unitary, indivisible insight or ability. Rather there are various phonemic insights (e.g., being able to judge which is a longer word in acoustic duration or being able to rhyme words, knowing that toad is composed of three distinctive-albeit overlapping and abstract-sounds, being able to say cat without the $/ \mathrm{t} /$ ). Some phonemic abilities (such as phoneme blending) appear prerequisite to learning to read, whereas other abilities (such as phoneme deletion) may be outcomes of learning to read (Perfetti, Beck, Bell, \& Hughes, 1987). There is converging evidence from both experimental and longitudinal studies conducted in several countries that some form of phonemic awareness is necessary to successfully learn to read alphabetic languages (Blachman \& James, 1985; Bradley \& Bryant, 1983; Elkonin, 1963, 1973; Fox \& Routh, 1975; Juel et al., 1986; Lundberg, Oloffson, \& Wall, 1980; Share, Jorm, Maclean, \& Matthews, 1984; Tornéus, 1984; Tunmer \& Nesdale, 1985; Williams, 1984).

Low socioeconomic status Black and Hispanic children are more likely than low socioeconomic status Anglo children to 
have poor phonemic awareness of school English, which hinders the development of decoding skill (Juel et al., 1986; Juel \& Leavell, in press). This may be a result of greater differences between school and home language for Black and Hispanic students, as well as cultural differences (which include such variables as time spent at home with word play, experience with nursery or Dr. Seuss rhymes, and general print exposure in storybook sharing). In a 15-month longitudinal study of British children from the age of 3 years, 4 months, Maclean, Bryant, and Bradley (1987) found (a) that there is a strong relation between children's early knowledge of nursery rhymes and the later development of phonological skill and (b) that phonological skill predicted early reading ability. Both relations were found after controlling for the effects of IQ and socioeconomic status.

The second component in the Simple View of reading is comprehension. Comprehension is the process by which the meanings of words are integrated into sentences and text structures. In spite of certain differences in form between specch and written text (cf. Rubin, 1980), in the Simple View a single underlying process is seen as producing both reading and listening comprehension. This implies that, given perfect word recognition, a child will read and comprehend a written text exactly as well as he or she would comprehend the text if it is spoken.

Children who come from homes in which language is used almost exclusively for direct (i.e., instrumental) communication may have difficulty with the decontextualized nature of communication in books and in school. On the other hand, children who have experienced decontextualized language by having been read to, by hearing language used for purcly conceptual discussions, or in other abstract contexts are better prepared for the language used in classrooms. Such children are also likely to be familiar with story structures and complex syntax and have richer vocabularies and developed concepts that will foster reading (as well as listening) comprehension of books. There is evidence that suggests minority and low socioeconomic status children are more likely to lack extensive experience with decontextualized language (Heath, 1983; Snow, 1983). As measured by standardized tests, the children in my research were below average in school language and listening comprehension at both the beginning and end of first grade.

The Simple View also considers writing to be composed of two basic factors, spelling and ideation. Just as learning to read words appears to require a degree of phonemic awarcness, so does spelling (Bradley \& Bryant, 1983; Juel et al., 1986; Lundberg et al., 1980). Children's invented spellings are created from letter name knowledge coupled with some degree of phonemic awareness. Read (1971, 1975, 1986) showed that there is a phonetic reason for certain nonstandard spellings frequently produced by young children. Schreiber and Read (1980) state that

children's spelling is phonetic, not merely in the expected sense that it represents each phoneme of English more or less consistently, but also in the sense that it represents details of pronunciation that adults are unaware of. A spelling such as "SIK" for "sink" is phonetically accurate in that for many, if not most pronunciations, "sink" does have only three phonetically distinct segments: [slk]. Any trace of a velar nasal that does occur is typically so short that it is by no means obvious that it is the "same sound" (same phoneme) as the one that occurs at the end of "sing" [sĩn]. (p. 212)

In comparison with such sophisticated spelling, Juel, Griffith, and Gough (1985) found that first-grade children who lacked phonemic awareness (as well as spelling-sound knowledge) made spelling errors that often seemed unrelated to phonetic elements (e.g., spelled rain as yes or wnishire). The children in their study lived in a low socioeconomic status area and may represent a different population of children than Read's subjects (who are usually not lower socioeconomic status children). It may be fairly hypothesized that the child who spells rain as yes has not engaged in writing activities as frequently as the child who spells rain as rane.

The second component of the Simple View of writing is ideation. Idcation is the ability to generate and organize ideas. The term is used broadly to encompass both the generation of creative thoughts and their organization into sentence and text structures. The lower socioeconomic status child, who may not have been read to as much as the higher socioeconomic status child, is likely to come to school with less knowledge of stories and fewer ideas for their creation.

Our models of reading and writing may seem somewhat simplistic at first. It should be recognized that each component (e.g., ideation) is complex in its own right and may be broken down into many subcomponents. But only two components of each model (i.e., spelling and ideation for writing, word recognition and comprehension for reading) seem necessary to characterize both the primary lower level skill (i.e., spelling or word recognition) and the primary higher level skill (i.e., ideation or comprehension) that form the central components of writing or reading.

Poor lower order processes may impede the development of higher order processes. Until the lower order process of spelling is somewhat automatic-at least for a corpus of high frequency words-the attention of the writer may be diverted from higher order composing processes (Bereiter, 1980; Gundlach, 1981; Scardamalia, 1981). The development of automatic lower level processing of words may also be required for attention to be fully focused on comprehension when reading (LaBerge \& Samuels, 1974). It seems clear that early efficient word recognition leads to better comprehension than does the reverse order (Calfee \& Piontkowski, 1981; Lesgold, Resnick, \& Hammond, 1985).

In the model called the Simple View, if someone is a poor reader, then he or she must be either a poor decoder, a poor listener, or both. If someone is a poor writer, then he or she must be either a poor speller, a poor generator of ideas, or both. In this study I investigated whether the sample of children who were poor readers and writers fit these models, and if so, where their problems began.

\section{Method}

\section{Subjects}

The children attended one large, neighborhood elementary school and lived in a low socioeconomic status area of small houses, du- 
plexes, and apartments in Austin, Texas. Many of the children's parents were either enlisted military personnel or other nonmilitary employees of a nearby Air Force base. As a result of the transient nature of this population, the study began with 129 children in first grade and ended with 54 children at the end of fourth grade. Data are presented in this study on the 54 children who remained in the school from first through fourth grade. The children were $26 \%$ Anglo, $31 \%$ Black, and $43 \%$ Hispanic Americans. There were 31 girls and 23 boys.

The children were in eight different classrooms in first grade, seven classrooms in second grade, and six classrooms in the third and fourth grades. The children were instructed with basal series that were eclectic in nature, blending sight word, phonics, and use of context approaches to word identification. The basal program was supplemented in first and second grade with a synthetic phonics program developed by the local school district.

\section{Procedure}

The measures and interviews given to the children are detailed below.

Phonemic Awareness Test. In October and April of each grade except the fourth, we administered the Phonemic Awareness Test developed by Roper/Schneider (1984). By the end of third grade, the children had reached ceiling on the test. This oral test has six subtests, each with seven items, and is individually administered. The subtests measure skill in phonemic segmentation, blending, deletion of first phoneme, deletion of last phoneme, substitution of first phoneme and substitution of last phoneme. The seven alpha coefficients, representing the average of all possible split-half reliabilities, are greater than .7 for all subtests. Details on test development can be found in Roper/Schneider (1984).

Decoding. In October/November and April of each grade the Bryant Test of Basic Decoding Skill (BTBDs; Bryant, 1975) was individually administered. The Bryant test consists of 50 pseudowords, which children read aloud. The first 20 pseudowords are CVCs (consonant-vowel-consonants, e.g., buf, dit, nuv). The next 20 items are more complex single syllable pseudowords (e.g., yode, shi, fler, cleef). Only the last 10 items have more than one syllable (e.g., cosnuv, uncabeness). The test reliabilities (Cronbach's alpha) were between .96 and .90 in each grade.

Word recognition. At the beginning of first grade, we had each child read a list of 10 words that would appear in their first preprimer. Only one child could read more than five of these words; most children could not read any. Several times each year each child was asked to read a list of the core vocabulary words from each book in their basal reading series. Each child was tested only on those words that the individual had actually covered in the basal series; in other words, a child was not asked to read words from the first third-grade reader until the child had rcad the text. The percentage of words each child correctly read aloud from each reader list was calculated.

In April/May of each grade the Iowa Test of Basic Skills (ITBS; Hieronymous, Lindquist, \& Hoover, 1980) was administered by the school. The vocabulary subtest requires the child to find which of four printed words labels a picture. It measures word recognition as well as vocabulary. The composite test-retest reliability on the ITBS is .98 .

The Wide Range Achievement Test reading subtest was administered in April of each grade (WRAT; Jastak, Bijou, \& Jastak, 1978). The WRAT reading subtest consists of 75 words (e.g., cat to aborigines). Children were individually asked to read the words aloud. The test-retest reliability is .96 .

Listening comprehension. The Metropolitan Readiness Test (MRT; Nurse \& McGauvran, 1976) was administered by the school in September of first grade. The MRT language subtest assesses school language and listening comprehension. The child marks pictures that correctly illustrate the meaning of orally presented short passages. The test-retest reliability of this subtest is .72. Similar to this subtest is the listening comprehension subtest of the ITBS. It was used as a year-end measure of listening comprehension in each grade.

Reading comprehension. The reading comprehension subtest of the ITBS was used to assess reading comprehension of both sentences and passages.

Place in series. Each child's place in his or her basal reader was determined. This measure represents the number of words the child had seen in running text in the readers.

Home reading. Each year the children were asked about their reading behaviors at home. The testers inquired about what (if anything) they read at home. They were asked about titles, authors, and plots of books they read. The children were also asked, over a period of several weeks, how many days or nights they read at home.

Attitude toward reading. Each year the children were asked a scries of questions about their attitude toward reading. Some questions focused on which of two activities they would rather do. For example: Would you rather watch television or read? Would you rather play with friends or read? Would you rather clean your room or read? The children were also asked, Do you like to read? Why?

$I Q$. At the beginning of second grade the Vocabulary and Block Design subtests from the Wechsler Intelligence Scale for ChildrenRevised (WISC-R; Wechsler, 1974) were administered. Results of these two subtests were summed to form an estimated IQ score. The testretest reliability is .86 on the WISC-R Vocabulary subtest and .85 on the Block Design subtest.

Spelling. In April of each grade the WRAT spelling subtest was administered. The spelling subtest requires a child to write words pronounced orally by the tester. The maximum number of words to be spelled, depending on performance, is 45 . The test-retest reliability for the spelling subtest is .97 . The ITBS spelling subtest was used as another measure of spelling. This subtest requires recognition of words that are incorrectly spelled.

Writing. In February and April of first grade, November and April of second grade, and January in third and fourth grades, each child was shown the same colorful picture of animals in a schoolroom setting and asked to write a story about what might be going on in the picture. In November of fourth grade, the children were asked to write a story about "The Friendly Ghost." Before beginning the story, each child was encouraged to talk about what a ghost is.

In both the animal and the ghost stories the children were told to spell words as best they could, but not to worry about spelling. After they wrote the story they read it back to the testers to resolve any possible discrepancies about words they had used. (These rereadings were later used by the raters to resolve ambiguities resulting from inadequate spelling.)

A score was assigned to each sample on the basis of the judgments of two raters. A representative writing sample for each rating was used as a guide for assigning these scores.

In second, third, and fourth grade, the same scoring guidelines were used. These scores ranged from 1 (low) to 9 (high). A score of 1 was assigned when the child wrote either a series of isolated words or text devoid of sentence structure. A score of 2 was assigned when the child had attempted to write complete sentences, but the sentences were not interrelated. A score of 3 indicated an attempt to write complete sentences to describe characters (i.e., the ghost or animals) or objects in the picture. A score of 4 was assigned when the child wrote a higher level, coherent description of characters or objects. A score of 5 indicated the child brought in background knowledge to create an elaborated description of characters or objects. A score of 6 was assigned when the child wrote an incomplete (or somewhat incoherent) episode. A score of 7 was given when the child wrote a 
complete episode that included several story grammar components (i.e., setting, initiating event, attempt, reaction, consequence). A score of 8 indicated a story containing more than one episode, with at least one episode containing several components of story grammar. A score of 9 was assigned if a story contained several fairly complete episodes, with a storyline or bridge to connect the episodes.

In first grade there were few children who wrote anything higher level than simple descriptions of the animal picture, and thus different scoring criteria had to be used than that used in the other grades. In first grade a score of 1 indicated that the child had produced either drawings in lieu of text, meaningless tangles of letters, or lists of words that were either not related or only tangentially related to the picture. A score of 2 was assigned to samples that contained occasional groups of related words, lists of words related to the picture, or barely comprehensible language. Scores of 3 through 7 were assigned to the remaining samples on the basis of relatedness or completeness of parts of the produced text.

Raters were instructed to disregard spelling but instead to consider level of story development, syntactic maturity, and richness of vocabulary when assigning a score. On occasion, a written sample would not quite fit any of the guidelines for the above categories and was assigned a score whose criteria it most resembled. The average interrater reliability was .86 (Pearson's $r$ ).

Ideas. A week or two after the children had written their last animal story in a grade, we asked each to orally tell a story about the picture. The oral stories were tape recorded and later transcribed and rated according to the same 1 to 9 criteria described above for writing in second through fourth grade.

\section{Results and Discussion}

\section{Do the Same Children Remain Poor Readers Year After Year?}

The reading development of the bottom quartile of children in reading comprehension at the end of first grade was examined. This bottom quartile consisted of 29 children who scored no better than a 1.2 grade equivalent on the ITBS Reading Comprehension subtest. The mean of these children's scores on the subtest was K6 at the end of first grade.

Of these 29 children, 24 remained in the school at the end of fourth grade. Two had been retained at the end of first grade, and three had left the school. Of the 24 remaining, all but 3 were still poor readers in fourth grade. Twenty-one were still reading at least 6 months below an appropriate grade equivalent at the end of fourth grade. These children were reading at no greater than a 4.2 grade equivalent on the ITBS Reading Comprehension subtest, with a mean for the group of grade equivalent 3.5.

Of the 86 children who were average or good readers at the end of first grade, 30 remained at the end of fourth grade. Of these 30,26 were still average or good readers, and 4 had slipped to below a 4.3 grade equivalent on the ITBS.

The probability that a child would remain a poor reader at the end of fourth grade, if the child was a poor reader at the end of first grade was .88 ; the probability that a child would become a poor reader in fourth grade if he or she had at least average reading skills in first grade was .12. The probability that a child would remain an average reader in fourth grade if the child had average reading ability in first grade was .87; the probability that a child would become an average reader in fourth grade if he or she was a poor reader in first grade was only .13. The evidence in this sample of children indicates that the poor first-grade reader almost invariably remains a poor reader by the end of fourth grade.

\section{Do the Same Children Remain Poor Writers Year After Year?}

Early writing skill did not predict later writing skill as well as early reading ability predicted later reading ability. This may be attributed in part to the curricular emphasis at our research school on reading, as opposed to writing, in first grade.

The correlation between writing at the end of first grade and writing in fourth grade was $.38, p>.01$, but the correlation increased with each subsequent grade level. The correlation between end-of-year second grade writing and fourth grade writing was $.53, p<.001$. The correlation between third and fourth grade writing was $.60, p<.001$.

\section{What Skills do the Poor Readers Lack?}

The children who became poor readers entered first grade with little phonemic awareness. The modal score for this group on the phonemic awareness test administered at the beginning of first grade was 0 . The mean score on this test for the children who became good readers (21.7) was considerably higher than that of the poor readers (4.2). By the end of first grade, the good readers had a mean score on the phonemic awareness test that approached ceiling (37.5). The poor readers made considerable gains in phonemic awareness in first grade, ending the year with a mean score of 18.6. The poor readers did not approach ceiling on the phonemic awareness test until the end of third grade, when their mean score was 36.2 .

Growth in spelling-sound knowledge was initially slow for the poor readers, and they never reached the level of the average and good readers. Nine of the poor readers could not read a single pseudoword on the BTBDs at the end of first grade, despite a year of phonics instruction. (These 9 children had little or no entering phonemic awareness.)

At the end of fourth grade, all but 2 poor readers were at least one standard deviation below the good readers on the BTRDS. The majority of the poor readers still could not decode all the monosyllabic pseudowords (e.g., buf) on the test by the end of fourth grade (see Table 1).

If the 2 poor readers in fourth grade who were good decoders had good listening comprehension, they would contradict the Simple View of reading. But this was not the case; both children had poor listening comprehension, one standard deviation below that of the good readers. Although there are many references in the literature to poor readers who are "word-callers," they were not found within this sample. The 2 poor readers who were good decoders could not comprehend well whether the input was oral or written.

There were 3 children who were poor decoders but had average listening comprehension. This is exactly the pattern that so-called dyslexic children should exhibit. But all the rest of the poor readers were also poor listeners. 
Table 1

Means and Standard Deviations for Reading Variables for Good and Poor Readers

\begin{tabular}{|c|c|c|c|c|}
\hline \multirow[b]{2}{*}{ Variable } & \multicolumn{2}{|c|}{$\begin{array}{l}\text { Poor } \\
\text { readers }\end{array}$} & \multicolumn{2}{|c|}{$\begin{array}{l}\text { Good } \\
\text { readers }\end{array}$} \\
\hline & $M$ & $S D$ & $M$ & $S D$ \\
\hline \multicolumn{5}{|c|}{ ITBS reading comprehension } \\
\hline Grade 1 & K6 & .4 & 2.4 & .4 \\
\hline Grade 2 & 1.7 & .5 & 3.8 & .7 \\
\hline Grade 3 & 2.6 & .4 & 4.8 & .8 \\
\hline Grade 4 & 3.5 & .3 & 5.9 & .8 \\
\hline \multicolumn{5}{|c|}{ ITBS listening comprehension } \\
\hline Grade 1 & 1.4 & .5 & 1.5 & .5 \\
\hline Grade 2 & 2.5 & .6 & 3.2 & .5 \\
\hline Grade 3 & 2.5 & .8 & 4.9 & .9 \\
\hline Grade 4 & 2.6 & .8 & 5.2 & .9 \\
\hline \multicolumn{5}{|l|}{ BTBDS (End of year) } \\
\hline Grade 1 & 8.3 & 9.2 & 24.9 & 11.9 \\
\hline Grade 2 & 19.6 & 5.9 & 36.0 & 7.8 \\
\hline Grade 3 & 28.7 & 11.7 & 41.4 & 6.4 \\
\hline Grade 4 & 28.4 & 9.2 & 42.6 & 7.2 \\
\hline \multicolumn{5}{|c|}{ WRAT word recognition } \\
\hline Grade 1 & 12.9 & 5.2 & 26.4 & 7.5 \\
\hline Grade 2 & 26.7 & 8.7 & 44.6 & 10.3 \\
\hline Grade 3 & 35.6 & 7.3 & 45.5 & 9.2 \\
\hline Grade 4 & 39.1 & 6.4 & 54.7 & 7.1 \\
\hline \multicolumn{5}{|c|}{$\begin{array}{l}\text { ITBS vocabulary } \\
\text { (word recognition) }\end{array}$} \\
\hline Grade 1 & 1.5 & .4 & 2.4 & 6 \\
\hline Grade 2 & 2.1 & .6 & 3.2 & .4 \\
\hline Grade 3 & 3.1 & .4 & 4.2 & .5 \\
\hline Grade 4 & 3.5 & .7 & 5.8 & .7 \\
\hline
\end{tabular}

Note, $\quad$ ITBS = Iowa Test of Basic Skills; BTBDS = Bryant Test of Basic Decoding Skills; WRAT $=$ Wide Range Achievement Test. ITBS score grade equivalents are presented here for convenience of interpretation. Raw scores were used in data analysis.

Poor fourth-grade readers were mainly children who were neither competent at decoding nor competent listeners (see Table 1). For each grade, word recognition on the WRAT was more predictive of ITBS reading comprehension than was listening comprehension on the ITBS. The impact of listening comprehension steadily rose with each grade level. In first grade, word recognition accounted for $44 \%$ of the variance in a hierarchical regression predicting reading comprehension (after controlling for the influence of listening comprehension), whereas listening comprehension had no unique influence. By fourth grade, word recognition still made a unique contribution of $25 \%$, but listening comprehension also made a unique contribution of $12 \%$.

\section{What Skills do the Poor Writers Lack?}

The mean score on "The Friendly Ghost" story was 4.8 $(S D=2.0)$. The mean score on the animal picture story in fourth grade was $5.0(S D=2.3)$. The correlation between the two writing samples in fourth grade was $.83, p<.001$. In fourth grade, 21 children had a mean of 3.5 or below on the combined writing scores. None of these children scored above a 5 on either writing sample. That is, 21 children were still writing descriptions rather than stories at the end of fourth grade.
Fourth-grade students with scores one standard deviation below the average WRAT spelling of the entire sample were labeled poor spellers. Fourth-grade students with an oral story production score of not more than 3.0 were defined as poor generators of story ideas. Using these criteria, 7 of the 21 poor writers had good spelling but poor ideas. Seven poor writers had good ideas but poor spelling. Seven poor writers had both poor ideas and poor spelling. As the Simple View would predict, no poor writers who had good spelling and good ideas were found in my study.

Although written samples were not evaluated in terms of spelling, this lower level skill seems to control to some degree the act of writing. This seems especially likely in the first grade, when children in a school setting may have been unwilling to try to write words that they could not spelleven though they were encouraged to do so in my study. It may also be just too difficult to write a story when one has to struggle with how to write the words. Spelling had more of an impact on first-grade writing than it did on fourth-grade writing. In a hierarchical regression predicting written animal stories in first grade, spelling accounted for $29 \%$ of the variance (after controlling for the influence of ideas), whereas in fourth grade spelling accounted for $10 \%$ of the variance. The influence of the higher level skill (i.e., ideas) on the written stories was apparent in each grade level's writing, however. The influence of ideas on the written stories also increased in impact with each grade. In first grade ideas accounted for $8 \%$ of the variance (after controlling for the influence of spelling); by fourth grade the impact of ideas had increased to account for $30 \%$ of the variance.

\section{What Factors Seem to Keep Poor Readers From Improving?}

A primary factor that seemed to keep the poor readers from improving was their poor decoding skill. The poor readers at the end of fourth grade had not achieved the level of decoding on the BTBDS that the good readers had achieved by the beginning of second grade. This lack of decoding skill prevented the poor readers from being able to read as much text-both in and out of school-as the good readers, which appeared to create further problems, as will be described later.

By the end of first grade, the good readers had seen, on average, 18,681 words in running text in their basal readers. In contrast, the poor readers had seen, on average, 9,975 words, about half as many. After first grade, differences in exposure to print in school became more complex to estimate because some poor readers were asked to reread basals previously covered. By simply counting words children were exposed to in readers (whether read or reread), it appeared in my study that the difference in exposure to print between good and poor readers grew larger with each grade. Many poor readers were still in beginning third-grade readers at the end of fourth grade. By contrast, the good readers had finished the fourth-grade reader. The good readers, on average, had read about 178,000 words in running text in their basal readers by the end of fourth grade, whereas the poor reader had read less than half of that-about 80,000 words. 
After second grade there also appeared to be wide differences in the amount of reading done out of school. The children were asked several questions about their reading habits at home. Although such data are not always reliable, a very close rapport developed between the children and the testers, and I believe that these self-reports are reasonably accurate. One of the questions the children were asked (over the course of several weeks each year) concerned the number of nights they read at home each week. The average number of nights reported per week by each group of readers is shown in Figure 1. Neither group of readers indicated they read much after school in first or second grade; but in third and fourth grade reading after school became quite frequent for the good readers. The good readers also could tell us the authors or titles or plots of many of the books they were reading, whereas few poor readers could supply such information.

The more frequent reading experiences-both in and out of school-of the children who learned to read well early in school likely contributed to the steadily widening gulf in listening comprehension (i.e., knowledge of vocabulary, concepts, text structures, syntax, and pragmatics) between the good and poor readers (see Table 1). The means of both the group of children who would become good readers and those who would become poor readers were in the 4th stanine (i.e., below the 39th percentile) on the MRT Language subtest (School Language and Listening Comprehension) at the beginning of first grade. At the end of first grade, both groups were still low average in listening comprehension on the ITBS. But unlike good readers, poor readers made almost no progress in listening comprehension after second grade. Poor readers ended fourth grade with a mean grade equivalent of 2.6 on the ITBS Listening Comprehension subtest compared with the good reader's mean score of 5.2.

It seems apparent that poor readers read little voluntarily, partly because reading was so difficult for them, and reading experiences in school must have been rather aversive. Throughout the grades each child in the study read a list of core vocabulary words from his or her basal reader. This list

$\rightarrow$ Poor Roeders Average ond Good Recders

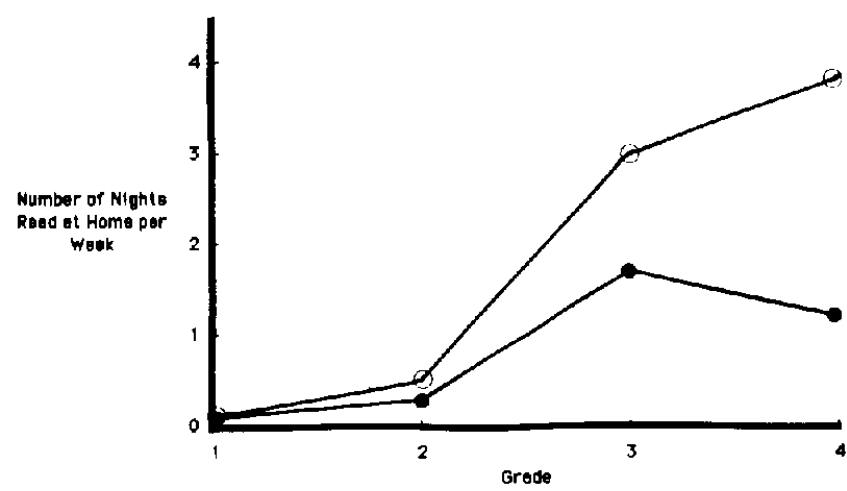

Figure 1. Mean number of nights per week poor and average to good readers read at home by themselves. was individualized for each child and included only words already seen in the basal. Usually reading educators recommend that students be given textbooks in which they can read at least $90-95 \%$ of the words in order to allow easy comprehension. In Figure 2 is shown a bar-graph comparison between the basal word reading of average/good readers and poor readers in each grade level book (no matter what grade level they were at when they read the book). The poor readers rarely correctly read even $80 \%$ of the words. For these children, reading each year in school was at best difficult and certainly not a successful experience.

We used a variety of questions to ascertain the children's attitudes toward reading. We asked them to select which of two activities they would rather do and why. For example, when asked whether they would rather watch television or read, about $70 \%$ of both good and poor readers said they would prefer to watch television; when asked whether they would rather play with friends or read, about $70 \%$ of each group said they would rather play. When asked whether they would rather clean their room or read, only $5 \%$ of the good readers said they would clean, whereas $40 \%$ of the poor readers preferred to clean-one child stated, "I'd rather clean the mold around the bathtub than read."

The fourth-grade children were also asked, "Do you like to read? Why?" Whereas 26 good readers answered with an unqualified yes to liking to read, only five poor readers responded yes.

Some typical reasons that good readers gave for liking to read were "You get neat ideas," "You get to picture things in your mind and use your imagination," "You learn new things from books," "I learn new words," "You know what happens in the story and you might learn from the mistakes of people in the stories," "It's fun to pretend like you're the one in the book," and "It keeps you going to see what happens next."

Poor fourth-grade readers seemed to read little because they hated reading (which several children said) or because of the failure experiences associated with reading. The most common response of the poor readers to why they did not like to read was that it was boring.

\section{What Factors Seem to Keep the Poor Writers From Improving?}

Poor readers appear to become poor writers. The correlation between writing and reading comprehension was $.27, p$ $<.05$ in first grade, $.39, p<.01$ in second grade, $.43, p<.01$ in third grade, and $.52, p<.001$ in fourth grade. By fourth grade 17 of the 25 poor readers were poor writers, whereas only 4 af the 29 good readers were poor writers.

Of the 4 good readers who were poor writers, 3 were good spellers but produced as poor oral stories as their written stories. The other child had good story ideas but was a poor speller.

Of the 17 poor writers who were also poor readers, 11 could neither write nor tell a good story. They lacked what 1 called story ideas (i.e., knowledge of story structures and the delivery of interesting story episodes). Of these 11 children, 7 were also poor spellers. The 6 poor readers who had good ideas were all poor spellers. 


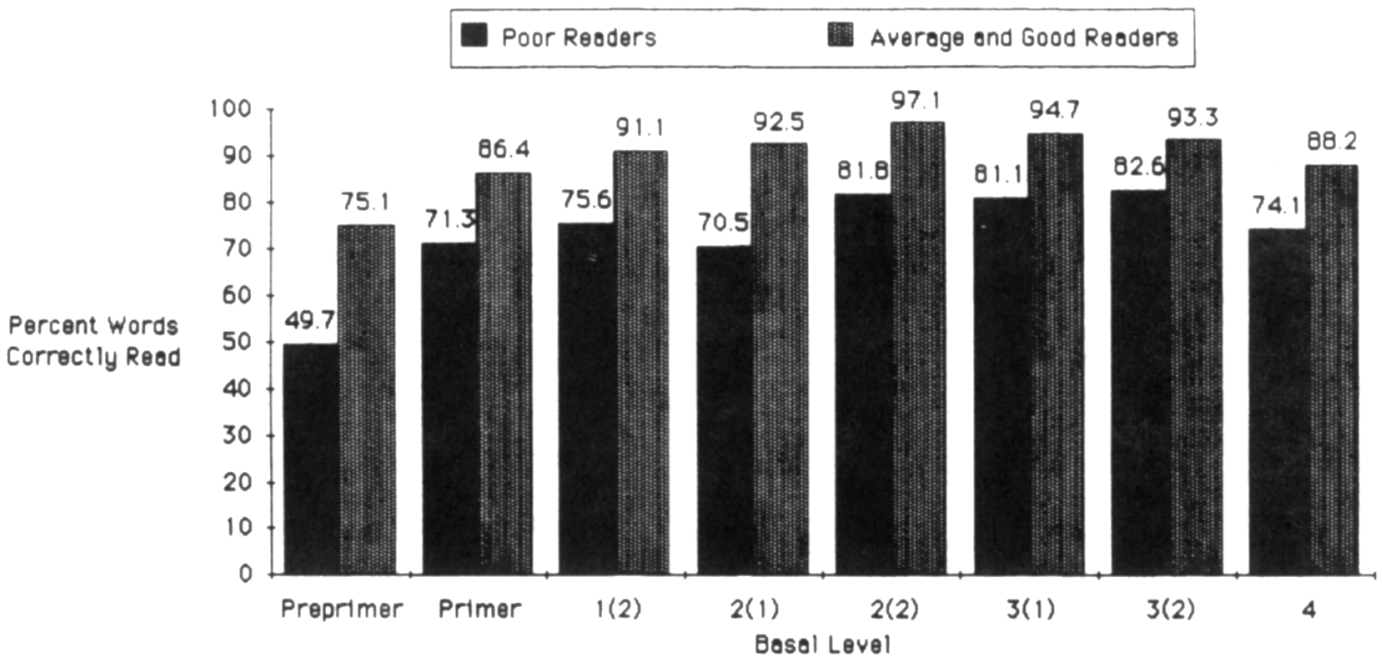

Figure 2. Mean percentage of words correctly read after reading each grade level basal book. (In first grade, there are three book lists: Preprimer (combining words in the three preprimers), Primer, and the 1[2] reader. In second and third grade, there are two basal readers. In fourth grade there is only one basal reader. Each child was tested only on the books that he or she covered in class. Several poor readers never got to the 3[2] or fourth-grade basal.)

Through the years the good readers' proficiency in producing ideas steadily grew, whereas poor readers made no apparent progress in their ability to tell an oral story from first to fourth grade (see Table 2). Most poor readers were still telling and writing descriptions rather than stories in the fourth grade. These descriptions usually amounted to little more than an expanded list of what was seen in the animal picture (e.g., "It is a big classroom. They have seven desk in there classroom. They have five pictures in it ...") or a simple description of "The Friendly Ghost" (e.g., "There was a ghost but he was a friendly ghost. He will help other people ...").

By at least fourth grade most good readers were writing stories that included some elements of story grammar (i.e., setting, elaborated description of characters, and at least one episode). Their animal stories sometimes involved real classroom situations (e.g., "Once upon a time there was a teacher who was talking to Roger. She asked him if he did his homework..."). Their animal stories often involved quite imaginative story lines. An example of the latter is the following excerpt from a very long story about the "animal class" on a field trip:

They went hiking up a very, very, ... very long trail. They hiked for hours and hours. Then they got lost a sand storm came and covered up the trail. Everyone got very scared.

It was finally dawn then Lisa ground squimel found a cave. The class stayed there overnight thank god they brought their lunches and had that for dinner ...."

The good readers' use of imaginative story lines, more story grammar elements, and interesting vocabulary was also evident in their "Friendly Ghost" stories. These elements are illustrated in the opening line of a story by a good reader: "One day a girl name Magi walked down a chilly street on the way home...."

The more frequent reading experiences of the good readers probably led to better story ideas (as well as knowledge of story structures and vocabulary with which to express those ideas). A hierarchical regression predicting the children's oral stories in each grade supported this notion. IQ was entered first in the regression, accounting for from $16 \%$ of the variance

Table 2

Means and Standard Deviations for Writing Variables for Good and Poor Readers

\begin{tabular}{|c|c|c|c|c|}
\hline \multirow[b]{2}{*}{ Variable } & \multicolumn{2}{|c|}{ Poor readers } & \multicolumn{2}{|c|}{$\begin{array}{l}\text { Good } \\
\text { readers }\end{array}$} \\
\hline & $M$ & $S D$ & $M$ & $S D$ \\
\hline \multicolumn{5}{|c|}{ Writing (animal story) ${ }^{a}$} \\
\hline Grade 1 & 2.8 & 1.5 & 4.2 & 1.4 \\
\hline Grade 2 & 2.9 & 1.3 & 4.9 & 2.6 \\
\hline Grade 3 & 3.5 & 2.5 & 5.8 & 2.6 \\
\hline Grade 4 & 3.8 & 2.2 & 6.2 & 1.8 \\
\hline \multicolumn{5}{|c|}{ Ideas (oral animal story) } \\
\hline Grade 1 & 3.8 & 2.4 & 4.0 & 2.6 \\
\hline Grade 2 & 3.3 & 2.0 & 4.5 & 2.6 \\
\hline Grade 3 & 3.9 & 2.1 & 5.2 & 2.3 \\
\hline Grade 4 & 3.8 & 2.0 & 6.0 & 1.9 \\
\hline \multicolumn{5}{|l|}{ WRAT Spelling } \\
\hline Grade i & 4.9 & 2.6 & 12.5 & 2.7 \\
\hline Grade 2 & 12.7 & 3.5 & 19.1 & 3.3 \\
\hline Grade 3 & 19.5 & 4.4 & 23.6 & 3.3 \\
\hline Grade 4 & 20.5 & 3.4 & 27.5 & 3.8 \\
\hline \multicolumn{5}{|l|}{ ITBS Spelling' } \\
\hline Grade 1 & 1.4 & .4 & 2.7 & .7 \\
\hline Grade 2 & 2.2 & .4 & 3.5 & .9 \\
\hline Grade 3 & 3.3 & .4 & 4.6 & .9 \\
\hline Grade 4 & 4.2 & .6 & 5.7 & 1.0 \\
\hline
\end{tabular}

Note. $\quad$ WRAT $=$ Wide Range Achievement Test; ITBS $=$ Iowa Test of Basic Skills.

${ }^{a}$ Writing means are from the end-of-year stories in first and second grade. Means for first grade are based on different scoring criteria than the means for the other grades. ' ITBS score grade equivalents are presented here for convenience of interpretation. Raw scores were used in data analysis. 
in first grade to $10 \%$ of the variance in fourth grade. Place in series (the number of words read in the basal) was then entered. After controlling for $1 \mathrm{Q}$, place in series still accounted for a significant amount of variance in each grade. Place in series contributed $6 \%$ to the variance in first grade, but its contribution rose with each subsequent grade-accounting for $30 \%$ of the variance in fourth grade.

\section{General Discussion}

In this study, the poor first-grade reader was almost invariably still a poor reader by the end of fourth grade. The good first-grade reader almost invariably remained a good reader at the end of fourth grade. Other studies have found similar trends. Clay (1979) discusses results of a study of children learning to read in New Zealand, where reading instruction begins at age five:

There is an unbounded optimism among teachers that children who are late in starting will indeed catch up. Given time, something will happen! In particular, there is a belief that the intelligent child who fails to learn to read will catch up to his classmates once he has made a start. Do we have any evidence of accelerated progress in late starters? There may be isolated examples which support this hope, but correlations from a follow-up study of 100 children two and three years after school entry lead me to state rather dogmatically that where a child stood in relation to his age-mates at the end of his first year at school was roughly where one could expect to find him at 7:0 or 8:0. (p. 13)

It is interesting to note that in Sweden, where formal schooling does not start until age 7, Lundberg (1984) found similar results. Of 46 Swedish children with low linguistic awareness and low reading achievement in first grade, 40 were still poor readers in sixth grade. Lundberg, as in our study, linked the poor readers' problem to poor entering phonemic awareness. Lundberg found that linguistic awareness of words and phonemes in first grade correlated .70 with reading achievement in sixth grade.

In comparing the findings of Clay (1979), Lundberg (1984), and my study, it appears that age of entry into formal school reading instruction (whether age 5,6 , or 7 ) is not the critical variable. It may be that method of reading instruction also does not affect this trend. Certainly reading instruction in Clay's New Zealand study, with its emphasis on reading for meaning, use of context for word identification, and early emphasis on writing, contrasts with the synthetic phonics program and lack of substantial writing in first grade in my research school's curriculum. The same finding appears whether reading occurs in Swedish or English. Although certainly not definitive, these three studies suggest that despite age of school entry, method of instruction, or language, a child who does poorly in reading in the first year is likely to continue to do poorly.

It is unlikely that as poor readers get older they will change. The most recent National Assessment of Educational Progress report found that good 9-year-old readers from previous assessments were likely to remain good readers through secondary school (National Assessment of Educational Progress, 1985 , p. 33). Early success with reading appears critical.
There are many variables that need to be explored further in order to determine how early pedagogic practice can be improved. Home, preschool, and kindergarten influences on first-grade reading as well as teacher and curriculum influences in first grade should be studied. As I indicated earlier in this article, many studies in several countries have shown that skill in entering phonemic awareness has a powerful influence on reading and spelling acquisition, and this was a factor of particular interest to me in this study.

In my research the children who became poor readers entered first grade with little phonemic awareness. Although their phonemic awareness steadily increased in first grade, they left this grade with a little less phonemic awareness than that which the children who became average or good readers possessed upon entering first grade.

Tunmer and Nesdale (1985) showed that in first grade phonemic awareness affects reading comprehension indirectly, through phonological recoding (as measured by pseudoword naming). Juel et al. (1986) found the same relation. They further found, in a hierarchical regression predicting word recognition at the end of first grade, that phonemic awareness accounted for $49 \%$ of the variance after accounting for the influence of IQ (WISC-R block design and vocabulary subtests) and listening comprehension.

In my study, poor entering phonemic awareness appeared to contribute to a very slow start in learning spelling-sound correspondences. Nine of the poor readers could not read a single pseudoword on the BTBDS (e.g., buf) at the end of first grade-despite a year of phonics instruction. By the end of fourth grade the poor decoders had still not achieved the level of decoding that the average to good readers had achieved by the beginning of second grade.

Although in my research the poor decoder appeared doomed, Calfee and Piontkowski (1981) offer some hope that a school's program may change the outcome. They studied the reading development of 50 first-grade children from 10 classrooms in four schools. They compared end-of-year firstgrade development with end-of-year reading achievement in second grade. They found a moderately strong correlation between decoding skill in first grade and reading achievement in second grade $(r=.65)$, but there was considerable variation in this relation among the four schools. In one school the relation was virtually impossible to measure because so few children learned to decode; in another school, the ranking on the decoding test was almost identical to that on the reading achievement test. The exceptional case was a school in which the reading program in second grade appeared to promote a uniformly high level of reading achievement by the end of the year, despite students' success or lack of success in learning letter-sound correspondences in first grade (pp. 369-370). Unfortunately, the specific processes that made the second grade program at this school so successful remain unknown.

There is a need to develop ways to remediate quickly poor decoding, because poor early decoding appears to lead to additional problems in both reading and writing. Faulty decoding skill prevents poor decoders from reading as much as good decoders. By the end of first grade, the good readers in my study had seen about twice as many words in running 
text as the poor readers $(18,681$ vs. 9,975$)$. These findings are remarkably similar to those of Clay (1967). She estimated that a child who made superior progress in the first year of instruction and was in the high reading group read about 20,000 words, whereas the low middle reading group child read 10,000 words and the low group child only 5,000 words. Allington (1984) and Biemiller (1977-1978) have found similar differences among ability groups in exposure to print.

In my study the difference in exposure to print in school only increased with each grade. These in-school differences in exposure to print were further compounded by out-of-school differences in reading behaviors. The average good reader in fourth grade reported reading at home almost four nights per week; the average poor reader reported reading at home about once a week.

Nagy and Anderson (1984) postulate that "beginning in about third grade, the major determinant of vocabulary growth is amount of free reading" (p. 327). Stanovich (1986) states,

The effect of reading volume on vocabulary growth, combined with the large skill difference in reading volume, could mean a "rich get richer" or cumulative advantage phenomenon is almost inextricably embedded within the developmental course of reading progress. The very children who are reading well and who have good vocabularies will read more, learn more word meanings, and hence read even better. Children with inadequate vocabularies-who read slowly and without enjoyment-read less, and as a result have slower development of vocabulary knowledge, which inhibits further growth in reading ability. (p. 381)

Findings from my study are consistent with these statements. I did my research in a low socioeconomic status neighborhood school with a racially mixed population of children. Whether a result of the predominant (i.e., home) language being Spanish, or dialect differences, or other factors associated with low socioeconomic status, entering school language and listening comprehension was somewhat low both for those children who became good readers and those who became poor readers. By the end of second grade, the good readers had made substantial gains in listening comprehension. The poor readers made some gains in listening comprehension between first and second grade but made little gain thereafter (see Table 1).

The correlational nature of the data collected in my longitudinal study, however, precludes making a causal connection between the increased reading experiences of the good readers and their increased listening comprehension. Certainly an intervention study is called for to further test this hypothesis, as it seems particularly relevant to the understanding of the low socioeconomic status child.

Chall and Jacobs (1983), in a cross-sectional study of low socioeconomic status children, report that poor readers begin their reading deceleration first in word meanings, beginning around fourth grade. Because their study did not start until the children were in second grade and involves a crosssectional comparison, it is difficult to directly equate their results with those of my study. Whether poor general listening comprehension (e.g., oral vocabulary, knowledge of syntax) is brought to school at the beginning of first grade or does not appear in low socioeconomic status children until fourth grade, it remains a matter of deep concern because it eventually affects reading comprehension.

According to the Simple View, reading is the product of decoding and comprehension (i.e., listening comprehension). Indeed, by the end of fourth grade the poor readers appeared deficient in at least one and usually two areas, decoding and listening comprehension. Although in each grade word recognition was more predictive of reading comprehension than was listening comprehension, the impact of listening comprehension steadily rose with each grade level. It seems likely that this trend would continue into higher grades. Because there is less variation in decoding skill among students in each grade (i.e., they can all read words fairly well), reading comprehension will come to approximate their ability to comprehend text as if it were spoken to them (i.e., depend on their skill in reasoning, on their knowledge of vocabulary, syntax, pragmatics, and so on) (Curtis, 1980; Singer, 1976).

Similar to Chall and Jacobs (1983), my study found that poor readers tend to become poor writers. Whereas Chall and Jacobs did not observe this trend until after third grade, I found it somewhat earlier. It is not too surprising that poor readers are poor spellers. As previously indicated, poor readers tend to be exposed to less print than good readers, both in and out of school. Spelling depends to a great extent on word specific knowledge (Juel et al., 1986). Such knowledge can only be acquired through print exposure (e.g., knowledge that green is spelled with "ee" rather than grean or grene).

It may be surprising that poor readers do not grow as much as good readers in their ability to generate an oral story. As one good reader explained, however, he liked to read because "you get neat ideas." Children who do not read much likely do not gain as much in vocabulary as prolific readers (Nagy \& Anderson, 1984; Stanovich, 1986), and also they may not develop in knowledge of what constitutes a good story. In my study, this notion received support through a hierarchical regression predicting oral story ideas. After accounting for IQ in the regression, place in series (the number of words read in the basal) accounted for a rising portion of the variance with each grade-accounting for $30 \%$ by fourth grade.

My study supported the Simple View of writing; poor writers were either deficient in spelling, in the generation of ideas for stories, or in both.

In my research, a vicious cycle seemed evident. Children who did not develop good word-recognition skill in first grade began to dislike reading and read considerably less than good readers, both in and out of school. They thus lost the avenue to develop vocabulary, concepts, ideas, and so on that is fostered by wide reading. This in turn may have contributed to the steadily widening gulf between the good and poor readers in reading comprehension and written stories. This cycle seems to illustrate the "Matthew Effect" described by Stanovich (1986).

One may speculate on what the findings suggest to prevent the low socioeconomic status or minority child from becoming a poor reader. First, the study once again illustrates the criticality of phonemic awareness in learning to decode words. 
Juel et al. (1986) showed both that the low socioeconomic status or minority child frequently needs more phonemic awareness and also that children will not benefit from phonics instruction until they gain some phonemic awareness. My study suggests that low phonemic awareness contributes to slow acquisition of decoding and is one of the early contributors to the vicious cycle. It would appear that more phonemic awareness training should occur in preschools and kindergarten, and, if needed, even in first grade.

Clay (1979) found that many 6-year old children who were not making good progress learning to read could not hear the sound sequences in words. She proceeded to adapt a phonemic awareness training program developed by the Russian psychologist D. B. Elkonin to train these children (cf. Elkonin, 1973). She found that the children could learn and apply the strategy of analyzing the sound sequence of words. Such phonemic analysis training is now part of her Reading Recovery program, where it is particularly connected to sounding out and writing words.

It seems clear that instructors should not wait to build phonemic awareness until after the child has already experienced failure learning to read. A recent study by Lundberg, Frost, and Petersen (1988) showed that preschool children can be successfully trained to discover and manipulate the phonological elements in words. Their 8-month training program involved a variety of games, nursery rhymes, and rhymed stories. Danish children who went through the training program showed dramatic gains in certain phonemic awareness skills, such as phoneme segmentation skill, compared with children who did not go through the program. The preschool training had a facilitating effect on reading and spelling acquisition through second grade.

Second, educators must make certain that children learn to decode in first grade. Clay (1979) writes,

A strategy of analysing spoken words into sounds, and then going
from sounds to letters may be a critical precursor of the ability
to utilize the heuristic tricks of phonics. And many children may
not need phonic instruction once they acquire and use a sound
sequence analysis strategy. (p. 66 ; emphasis added)

Whether this strategy would eliminate a need for phonics instruction is intriguing but unclear; certainly children should learn to decode in first grade. If decoding skill arrives much later, it may be very hard to change the direction that reading achievement will take: Poor decoding skill leads to little reading and little opportunity to increase one's basic vocabulary and knowledge through reading, leaving a shaky foundation for later reading comprehension.

There is currently great attention in the literature to increasing the reading comprehension skills of older students. However, a recent review by Carver (1987) of studies that have attempted to tcach comprehension found little evidence that such efforts have much payofr. Many studies that have attempted to improve students' reading comprehension through development of vocabulary or metacognitive comprehension strategies show very little effect. It seems intuitively obvious that it would be very hard to make up for years of lost experiences with the words and concepts found in print with relatively short-term treatments. Although there is no doubt the higher order comprehension skills of older students need to be improved, the most straightforward way to achieve this goal in the future may be to concentrate on the rapid and early attainment of the lower level skills.

Third, for children who are not learning to decode and who are not reading much, every effort must be made both to keep them motivated to read and to keep up their listening comprehension so they do not fall so far behind in vocabulary, concepts, and so on. The age-old technique of reading to children often seems to fit the requirement nicely and should not be forgotten in the elementary grades.

Fourth, it appears likely that extensive reading (or listening to a lot of stories) is important to acquiring ideas with which to write one's own stories. The observed moderate correlation between good reading ability and good writing ability-which has been found in this and other studies-does not require an elaborate explanation, such as the currently popular view that this relation is the result of the similarity of the two thinking processes involved. Rather the correlation can be more parsimoniously explained by the fact that good readers simply read more and over time have experienced more ideas and vocabulary that can be incorporated into their writing. In the words of Steven Spielberg at the 1987 Academy Awards, "Only a generation of readers will spawn a generation of writers."

\section{References}

Allington, R. L. (1984). Content coverage and contextual reading in reading groups. Journal of Reading Behavior, 16, 85-96.

Bereiter, C. (1980). Development in writing. In L. W. Gregg \& E. R. Steinberg (Eds.), Cognitive processes in writing (pp. 73-96). Hillsdale, NJ: Erlbaum.

Biemiller, A. (1977-1978). Relationships between oral reading rates for letters, words, and simple text in the development of reading achievement. Reading Research Quarterly. 13, 223-253.

Blachman, B. A., \& James, S. L. (1985). Metalinguistic abilities and reading achievement in first-grade children. In J. Niles \& R. Lalik (Eds.). Issues in literacy: $A$ research perspective (pp. 280-286). Rochester, NY: National Reading Conference.

Bradley, L., \& Bryant, P. E. ( 1983). Categorizing sounds and learning to read-a causal connection. Nature, 301, 419-421.

Bryant, N. D. (1975). Diagnostic test of basic decoding skills. New York: Columbia University, Teachers College.

Calfee, R. C., \& Piontkowski, D. C. (1981). The reading diary: Acquisition of decoding. Reading Research Quarterly. 16. 346373.

Carver, R. P. (1987). Should reading comprehension skills be taught? In J. E. Readance \& R. S. Baldwin (Eds.), Research in literacy: Merging Perspectives (pp. 115-126). Rochester, NY: National Reading Conference.

Chall, J. S., \& Jacobs, V. A. (1983). Writing and reading in the elementary grades: Developmental trends among low SES children. Language Arts, 60, 617-626, 660 .

Clay, M. M. (1967). The reading behaviour of five year old children: A research report. New Zealand Journal of Educational Studies, 2 , $11-31$.

Clay, M. M. (1979). Reading: The patterning of complex behaviour. Auckland, New Zealand: Heinemann.

Curtis, M. (1980). Development of components of reading skill. 
Journal of Educational Psychology, 72, 656-669.

Elkonin, D. B. (1963). The psychology of mastering the elements of reading. In B. Simon \& J. Simon (Eds.), Educational psychology in the U.S.S.R. (pp. 165-179). London: Routledge \& Kegan Paul.

Elkonin, D. B. (1973). U.S.S.R. In J. Downing (Ed.), Comparative reading (pp. 551-579). New York: Macmillan.

Fox, B., \& Routh, D. K. (1975). Analyzing spoken language into words, syllables, and phonemes: A developmental study. Iournal of Psycholinguistic Research, 4, 331-342.

Gough, P. B., \& Tunmer, W. E. (1986). Decoding, reading, and reading disability. Remedial and Special Education, 7, 6-10.

Gundlach, R. A. (1981). On the nature and development of children's writing. In C. H. Frederiksen \& J. F. Dominic (Eds.), Writing: The nature, development, and teaching of written communication. Vol. 2: Writing: Process, development and communication (pp. 133152). Hillsdale, NJ: Erlbaum.

Heath, S. B. (1983). Ways with words. Cambridge, England: Cambridge University Press.

Hieronymous, A. N., Lindquist, E. F., \& Hoover, H. D. (1980). IOWA Test of Basic Skills. New York: Houghton Mifflin.

Jastak, J., Bijou, S., \& Jastak, S. (1978). Wide Range Achievement Test. Wilmington, DE: Jastak Associates.

Juel, C., Griffith, P. L., \& Gough, P. B. (1985). Reading and spelling strategies of first grade children. In J. A. Niles \& R. Lalik (Eds.), Issues in literacy: A research perspective (pp. 306-309). Rochester, NY: National Reading Conference.

Juel, C., Griffith, P. L., \& Gough, P. B. (1986). Acquisition of literacy: A longitudinal study of children in first and second grade. Journal of Educational Psychology, 78, 243-255.

Juel, C., \& Leavell, J. A. (in press). Retention and nonretention of "at risk" readers in first grade and their subsequent reading achievement. Journal of Learning Disabilities.

LaBerge, D., \& Samuels, S. J. (1974). Toward a theory of automatic information processing in reading. Cognitive Psychology, 6, 293 323.

Lesgold, A., Resnick, L. B., \& Hammond, K. (1985). Learning to read: A longitudinal study of word skill development in two curricula. In G. E. MacKinnon \& T. G. Waller (Eds.), Reading research: Advances in theory and practice (Vol. 4, pp. 107-138). New York: Academic Press.

Lundberg, I., (1984. August). Learning to read. School Research Newsletter. National Board of Education, Sweden.

Lundberg, I., Frost, J., \& Petersen, O. (1988). Effects of an extensive program for stimulating phonological awareness in preschool children. Reading Research Quarterly, 23, 263-284.

Lundberg, I., Oloffson, A., \& Wall, S. (1980). Reading and spelling skills in the first school years predicted from phonemic awareness skills in kindergarten. Scandinavian Journal of Psychology, 21, 628-636.

Maclean, M., Bryant, P., \& Bradley, L. (1987). Rhymes, nursery rhymes, and reading in early childhood. Merrill-Palmer Quarterly, $33,255-281$.

National Assessment of Educational Progress. (1985). The reading report card, progress toward excellence in our schools: Trends in reading over four national assessments, 1971-1984 (Report No. 15-R-01). Princeton, NJ: Educational Testing Service.
Nagy, W. E., \& Anderson, R. C. (1984). How many words are there in printed school English? Reading Research Quarterly, 19, 304330.

Nurse, J., \& McGauvran, M. (1976). Metropolitan Readiness Tests, Level II. New York: Harcourt Brace Jovanovich.

Perfetti, C. A., Beck, I., Bell, L. C., \& Hughes, C. (1987). Phonemic knowledge and learning to read are reciprocal: A longitudinal study of first grade children. Merrill-Palmer Quarterly, 33, 283-319.

Read, C. (1971). Pre-school children's knowledge of English phonology. Harvard Educational Review, 41, 1-34.

Read, C. (1975). Children's categorization of speech sounds in English. Urbana, IL: National Council of Teachers of English.

Read, C. (1986). Children's creative spelling. London: Routledge \& Kegan Paul.

Roper/Schneider, H. D. W. (1984). Spelling, word recognition, and phonemic awareness among first grade children. Unpublished doctoral dissertation, University of Texas at Austin.

Rubin, A. (1980). A theoretical taxonomy of the differences between oral and written language. In R. J. Spiro, B. C. Bruce, \& W. F. Brewer (Eds.), Theoretical issues in reading comprehension (pp. 41 1-438). Hillsdale, NJ: Erlbaum.

Scardamalia, M. (1981). How children cope with the cognitive demands of writing. In C. H. Fredericksen \& J. F. Dominic (Eds.), Writing: The nature, development, and teaching of written communication. Vol. 2: Writing: Process, development, and communication (pp. 81-104). Hillsdale, NJ: Erlbaum.

Schreiber, P., \& Read, C. (1980). Children's use of phonetic cues in spelling, parsing, and-maybe-reading. Bulletin of the Orton Society. 30. 209-224.

Share, D. L., Jorm, A. F., Maclean, R., \& Matthews, R. (1984). Sources of individual differences in reading achievement. Journal of Educational Psychology, 76, 1309-1324.

Singer, H. (1976). Substrata-factor theory of reading: Theoretical design for teaching reading. In $\mathrm{H}$. Singer \& R. Ruddell (Eds.), Theoretical models and processes of reading (2nd ed.). Newark, DE: International Reading Association.

Snow, C. (1983). Literacy and language: Relationships during the preschool years. Harvard Educational Review, 53, 165-189.

Stanovich, K. E. (1986). Matthew effects in reading: Some consequences of individual differences in the acquisition of literacy. Reading Research Quarterly, 21, 360-406.

Torneus, M. (1984). Phonological awareness and reading: A chicken and egg problem? Journal of Educational Psychology, 76, 13461358.

Tunmer, W. E., \& Nesdale, A. R. (1985). Phonemic segmentation skill and beginning reading. Journal of Educational Psychology, 77, 417-427.

Wechsler, D. (1974). Manual for the Wechsler Intelligence Scale for Children-Revised. New York: The Psychological Corporation.

Williams, J. P. (1984). Phonemic analysis and how it relates to reading. Journal of Learning Disabilities, 17, 240-245.

Received February 4, 1988

Revision received May 18, 1988

Accepted May 30, 1988 